Journal of Social Sciences 6 (2): 167-169, 2010

ISSN 1549-3652

(C) 2010 Science Publications

\title{
A Model of Appropriate Self-Adjustment of Farmers who Grow Para Rubber (Hevea brasiliensis) in Northeast Thailand
}

\author{
Montri Srirajlao, Worapol Aengwanich and Subunn Ieamvijarn \\ The Research Institute of Northeastern Arts and Culture, \\ Mahasarakham University, Maha Sarakham, 44000
}

\begin{abstract}
Problem statement: Para Rubber was an economic wood growing in Northeast Thailand playing economic and social role. The objectives of this research were to study: (1) the economic, social and cultural lifestyle and (2) the appropriate adjustment model of agriculturists or farmers growing Para Rubber in Northeast Thailand. Approach: The research area covered 6 provinces: Mahasarakam, Roi-ed, Khon Kaen, Nongkai, Udontani and Loei. The samples were selected by Purposive Sampling including: 90 experts, 60 practitioners and 60 general people. The instruments using for collecting data were: (1) The Interview Form, (2) The Observation Form, (3) Focus Group Discussion and (4) Workshop, investigated by Triangulation. Data were analyzed according to the specified objectives and presented in descriptive analysis. Results: The farmers' lifestyle in traditional period of Northeast Thailand was to earn their living from producing by themselves and sharing resources with each other including: rice farming, farm rice growing, vegetable garden growing, searching for natural food without cost wasting one's capital. When it was period of changing, the price of traditional industrial crop was lowered, the agriculturists began to grow Para Rubber instead since the promotion of governmental industrial section. For the economic, social and cultural changes, found that the agriculturists growing Para Rubber Plantation, had more revenue. But, the mechanism of market price and selling had stability was attached with political situation. For the pattern of adjustment of the agriculturists growing Para Rubber Plantation in Northeast Thailand, found that there was an adjustment in individual level for developing their self study by applying body of knowledge learned by experience of successful people by being employed in cutting Para Rubber in The Southern of Thailand as well as the academic support and selling to serve the need of farmers. Conclusion/Recommendations: Para Rubber was industrial crop in capitalism society. Therefore, it needed to be continuously supported in order to have balance on production.
\end{abstract}

Key words: Appropriate, self-adjustment, farmers, Para Rubber, Northeastern Thailand

\section{INTRODUCTION}

In 1990, The Office of Support Fund for growing Para Rubber provided support for the project promoting to grow Para Rubber in The Northeast Thailand in order to increase revenue for farmers. As a result, the farmers were more interested in this topic. According to the extension of the area for growing Para Rubber in large area, people growing Para Rubber were adjusted themselves and appropriate model. They applied knowledge in using local technology for selection and arrangement of the area, understanding in the types of Para Rubber Seed, growing young plant of Para Rubber by soaking a grafting in bag, determination of duration for arranging the line for growing, maintenance, using fertilizer, prevention by using the weed killer for getting rid of the disease as enemy of Para Rubber, cutting Para Rubber, equipment for cutting Para Rubber and equipment for making raw piece of Para Rubber affecting the increase of amount of Para Rubber Water and quality of production. For traditional agriculture inherited from the ancestors, it caused many problems including the abandon of Para Rubber Garden by the farmers, the farmers weren't interested in taking care of it. Besides, the area used to be grown the cassava, pineapple, sugar cane and fiber crops before and improved from deserted forest. Consequently, the farmers didn't pay attention in maintenance since they lacked of confidence in the product from growing Para Rubber. They weren't interested in taking care of Para Rubber Plantation. They didn't have knowledge and experience in growing Para Rubber Plantation and

Corresponding Author: Montri Srirajlao, The Research Institute of Northeastern Arts and Culture, Mahasarakham University, Maha Sarakham, 44000 Thailand Tel: +66-43-721686134 
support and maintain as well as technology in growing Para Rubber. As a result, the Para Rubber Crops were stunted or undeveloped Educational Technology and Communications.

According to problems as the above, the farmers searched for model of their appropriate adjustment for growing Para Rubber in The Northeast of Thailand, as clearer in more concrete form so that they could be self reliant. For their adequate model of adjustment, it consisted of: the decrease of capital for production, the use of vocational skill for production, the production wasn't over power, the collaboration of farmer group and making side lines for revenue as self reliant which would affect their income and be worthwhile.

Research objectives: The objectives of this research were to study:

- The farmers' lifestyle for growing Para Rubber plantation in the Northeast of Thailand

- The farmers' economic, social and cultural changes in growing Para Rubber Plantation in Northeast Thailand

- The farmers' appropriate model for growing Para Rubber in Northeast Thailand

\section{MATERIALS AND METHODS}

The studied area was the Northeast Thailand including research area of 6 provinces including: Mahasarakam, Roi-ed, Khon Kaen, Nongkai, Udontani and Loei. The research design was qualitative research. The process divided into the delimitation of research and research methodology. The samples provided information were selected by Purposive Sampling including: 24 experts, 60 practitioners and 120 general People. The instruments using for collecting data were: (1) The Interview Form, (2) The Observation Form, (3) The Focus Group Discussion, (4) The Triangulation for investigation. The findings were in descriptive analysis.

\section{RESULTS}

According to the farmers administered appropriate model in growing Para Rubber Plantation in Northeast of Thailand, it still lacked of skill in knowledge and understanding for the steps growing Para Rubber Plantation based on correct rationale of agriculture. Therefore, Thai farmers growing Para Rubber Plantation in Northeast of Thailand, needed to be adjusted their technique in growing Para Rubber. Practically, the adequate adjustment of farmers growing Para Rubber Plantation were brought. Consequently, they had knowledge, understanding, technique and steps in growing Para Rubber. They could be independent by lowering their capital of production, using vocational skill in producing, producing not more than power, collaboration of farmers and doing side line for earning revenue for self reliant which would affect their income and be worthwhile.

\section{DISCUSSION} follows:

According to the findings, could be discussed as

- For the farmers' lifestyle in growing Para Rubber Plantation in Northeast Thailand, it could be classified into 3 periods as follows: (1) traditional period, it was depended on rice farming, farm rice growing as major work, vegetable garden growing and searching for food from natural sources, exchanging things inside and outside community, (2) the period of changes when it was World War I, the government adapted economic structure by encouraging to grow fiber crops, cassava and sugar cane. Later on, social problem was reflected since it was a lot of deforestation because it was food origin. Moreover, the soil was in lower quality from growing crops many times. It was supported by the findings of Pratumrat (2005), found that the growing of commercial crop in the area of Toongkula-ronghai including Roi-ed, Mahasrakam, Surin and Buriram Provinces, which was the fiber crop in 1997, caused by the demand of foreign countries since in that period it was drought in Pakistan, a big exporters of the world. As a result, the price of fiber crop was very much increased. So, it was incentive for farmers in Northeastern of Thailand, for growing the fiber crop more. Furthermore, there were factories weaving bags for containing rice or other things. Then the cassava and sugar cane were grown all over The Northeast of Thailand. Besides, the lost of forest relating to security since there was a communism disseminating in Northeast of Thailand, (3) the period of alternatives, for the farmers' lifestyle during the period of alternatives, it was aimed to grow commercial crops for increasing revenue. The price for selling products included: (1) the first growing of Para Rubber Plantation in Northeastern Community, (2) the work offices played role in growing Para Rubber Plantation in Northeastern Community and (3) the origin of knowledge and technique in growing Para Rubber in Northeastern Community. For the first period in growing Para Rubber in Northeastern 
Community, found that there was an experimentation in growing Para Rubber at the pilot station of Department of Academic Agriculture, 15 rai each province, in Burirum, Surin and Nongkai Provinces (Kongchareon, 2003). The Para Rubber Crop was experimented to be grown in Northeastern of Thailand. According to Para Rubber Crop growing in many areas, it found that the Para Rubber Plants were well grown. It was supported by Deerasamee (1999) statement that the experimented plots growing Para Rubber Crop at the pilot station of Department of Academic Agriculture, still maintained the growth condition as an evidence. So, it was a starting point to enlarge the area for growing Para Rubber Crop to Northeastern of Thailand

- For the economic, social and cultural changes of farmers growing Para Rubber plantation in Northeastern of Thailand, in economic aspect, there was a production for living. For the starting period of growing, most of them had to increase capital in buying the chemical substance as pesticide and fertilizer by depending more on the loaning fund. It was supported by Prajanpon (2000a), found that there was no relationship between the factor and amount of credit and adjustment. For social aspect, the farmers lived together as relative system as the former time as well as collaborated as a group and developed network both inside and outside community for bargaining the mechanism of market price and helping members. It was supported by Prajanpon (2000b) findings that the group of farmers in order to support the farmers to solve the occurred problems relating to one's own need. Moreover, the members were supporters for farmer development in another way. Besides, there were communication system, public utility system and public service system covering and easily accessible to service and being convenient. For cultural aspect, the farmers were Buddhists with temples as a center in organizing religious ceremony and activities of community in order to inherit traditional monthly tradition as the usual. The 4 factors aspect of structure were changed into capitalism

- For the farmers' appropriate adjustment model in growing Para Rubber Plantation, the issues were found as follows: (1) for personal level, people had to develop self learning by applying body of knowledge and experience to be appropriate to new agricultural occupation, (2) the public sector had to provide support for capital and marketing, (3) the establishment of cooperative for helping the members, (4) the establishment of network with public sector and (5) the crop plantation and other occupations should be performed

\section{CONCLUSION}

For the appropriate model of adjustment of farmers growing Para Rubber garden in Northeast Thailand, the campaign in producing bio-fertilizer should be supported and enhanced by both of the public and private sectors so that the farmers growing Para Rubber garden would know how to mix fertilizer for use by themselves as well as producing bio-fertilizer and organic fertilizer for nourishing Para Rubber as much as possible in order to lower the capital for producing. Furthermore, it would help the soil to be fertile. So, it was necessary to extend body of knowledge for farmers who grew Para Rubber throughout Northeast Thailand.

\section{ACKNOWLEDGEMENT}

The research has been supported generously by the Mahasarakham University Research Fund. The authors would like to express their sincere appreciation for all of the support provided.

\section{REFERENCES}

Deerasamee, S., 1999. Growing Para Rubber Plantation. Sangpanyalerd Co. Ltd., Bangkok, ISBN: 974-87061-3-3, pp: 133-134.

Kongchareon, C., 2003. A Study of Economic feasibility in growing Para Rubber substituting industrial crop in Nongkai Province. Master of Science Thesis in Resource Management, Graduate School, Kasetsat University, ISBN: 974-353-972-4, pp: 16.

Prajanpon, L., 2000a. Factors affecting decision making in growing Para Rubber of farmers in Muang District. Loei Province. Master of Science Thesis, Khon Kaen University, ISBN: 974-676-984-7, pp: 17.

Prajanpon, P., 2000b. Relationship Some factors and adjustment of farmers growing Para Rubber in Northeast Thailand: A case study in Leoi Province. Master of Art Thesis, Khon Kaen University, ISBN: 74-678-284-3, pp: 66.

Pratumrat, P., 2005. The analysis of cost and benefit from growing Para Rubber in new growing area, Namsome District, Udontani Province. Master of Business Administration in Business Administration, Mahasarakam University, ISBN: 974-19-6167-7, pp: 78. 